\title{
"Silent" circulation of Trypanosoma spp. in Tabanids (Diptera: Tabanidae) and Cattle in a Tsetse free Range land of Ngaoundere (Adamawa-Cameroon)
}

\author{
Samuel ABAH ${ }^{1,2}$, Silas Lendzele SEVIDZEM ${ }^{3,4,5^{*}}$, Alexandre Michel NJAN NLOGA ${ }^{1}$, \\ Archile PAGUEM ${ }^{5,6}$, Abdoulmoumini MAMOUDOU ${ }^{7}$, \\ Jacques François MAVOUNGOU ${ }^{3,4}$ and Andre $\mathrm{ZOLI}^{7}$ \\ ${ }^{1}$ Department of Biological Sciences, Faculty of Science, University of Ngaoundéré, Cameroon. \\ ${ }^{2}$ Special Mission for Tse-tse fly Eradication, Ngaoundéré, Cameroon. \\ ${ }^{3}$ IRET, Department of Animal Biology, PO Box 13354, Libreville, Gabon. \\ ${ }^{4}$ Ecole Doctorale des Grandes Ecoles (EDGE), Laboratoire d'Ecologie Vectorielle (LEV-IRET), BP: 13354, \\ Libreville, Gabon. \\ ${ }^{5}$ Programme Onchocercoses field station of the University of Tübingen, P.O. Box 65, Ngaoundéré, Cameroon. \\ ${ }^{6}$ Institute of Evolution and Ecology, Department of Comparative Zoology, University of Tübingen, Auf der \\ Morgenstelle 28, 72076 Tübingen, Germany. \\ ${ }^{7}$ School of Veterinary Medicine and Sciences, University of Ngaoundéré, Cameroon. \\ *Corresponding author; E-mail: sevidzem.lendze@gmail.com; abadadaaba@yahoo.fr; Tel: +237656420010
}

\begin{abstract}
The Adamawa region falls within the tsetse belt of Cameroon but harbours isolated pockets of tsetse free range lands like Ngaoundere. There is no report on the occurrence of tsetse and bovine trypanosomosis in Ngaoundere. To provide information on this subject, two Vavoua traps were used to trap vectors of bovine trypanosomiasis and at the same time, blood was collected from cattle. Genomic DNA was extracted from buffy coat of cattle blood $(n=42)$ and biting flies $(n=53)$. The nested PCR was used to screen the samples for Trypanosoma spp. During the 14 days of trapping in November and December 2017 in Ngaoundere, 127 flies were documented and classified under two taxa: Tabanidae and Stomoxyini. Three Trypanosoma spp. DNA was isolated from tabanid (18.9\%) samples and identified as T. theileri, T. vivax and T. evansi and two of them that is $T$. theileri (4\%) and T. vivax (3\%) were also detected in cattle (7\%). There was no case of trypanosome DNA isolated from all the screened Stomoxyini. This result indicates the "silent" transmission of T. theileri and T. vivax by tabanids in the absence of glossines in Ngaoundere.
\end{abstract}

(C) 2020 International Formulae Group. All rights reserved.

Keywords: Trypanosomes, tabanids, stomoxyini, PCR, Ngaoundere, Adamawa-Cameroon. 


\section{INTRODUCTION}

Bovine trypanosomiasis is considered as one of the most important cattle diseases in Adamawa region of Cameroon (Mbahin et al., 2006). The last tsetse eradication of $1994 \mathrm{did}$ not include Ngaoundere because it was considered free of tsetse and trypanosomiasis. Because of fear of the re-introduction of tsetse and trypanosomiasis in tsetse free areas by neighbouring infested areas, deltamethrin coated screen barriers were pitched at the Ngaoundere hill by the special mission for tsetse erradication to prevent the re-infestation of Ngaoundere by wild tsetse from neighbouring and tsetse-infested North region. In Cameroon, the Adamawa plateau harbours several cattle markets (Motta et al., 2017) and receives cattle from neighbouring Chad, Sudan, Central African Republic, Nigeria and Niger which are potential sources for the introduction and re-introduction of new strains of vector-borne livestock diseases. Apart from commercial cattle, cattle of transhumant pastoralists from the aforementioned neighbouring countries come in contact with sedentary cattle thereby introducing different strains of Trypanosoma in local cattle through bites of local vectors. The report of Sevidzem et al. (2015) revealed the occurrence of mechanical vectors (Tabanids and Stomoxys) of bovine trypanosomiasis in the Adamawa plateau. Such vectors have been shown to acyclically and cyclically transmit trypanosomes (Boese et al., 1987; Desquesnes et al., 2003a; Desquesnes et al., 2003b; Taioe et al., 2017; Mounioko et al., 2018). The review document of Wells (1972) highlights the importance of mechanical transmission in the epidemiology of nagana. Wells (1972) stated that transmission of nagana in the absence of glossines is caused by mechanical vectors such as tabanids, stomoxyines and hippoboscids. The study of Mamoudou et al. (2016) reported the occurrence of high tabanid densities in several ecozones of the Far North region of
Cameroon. Some authors report that T. evansi is geographically most widespread trypanosome (Desquesnes et al., 2013) and was originally reported in Camels in Africa (Lun and Brun, 1992). In the tsetse free Far north region of Cameroon, Suh et al. (2017) reported $0.67 \%$ and $1.46 \%$ prevalence of $T$. vivax. The continuous usage of trypanocides and insecticides in Ngaoundere is an indication of the existence of trypanosomiasis and its mechanical vectors in the apparent absence of glossines. There is need to apply sophisticated tools like PCR to identify the Trypanosoma spp. occurring in cattle and biting flies. Bosson-Vanga et al. (2012) found out that PCR was far more specific than microscopy in trypanosome identification. The goal of the present study is to molecularly screen cattle and flies of trypanosomes in the tsetse free range land of Ngaoundere.

\section{MATERIALS AND METHODS \\ Study area}

The study was conducted in a herd located $25 \mathrm{Km}$ from the town of Ngaoundere and falls within the following geographical limits: latitude $07^{\circ} 11,887^{\prime} \mathrm{N}$ and longitude $013^{\circ} 34,919^{\prime}$ E. Ngaoundere is a major livestock production zone and is considered a tsetse free zone but hyper infested with other flies (Lendzele et al., 2019) (Figure 1). In addition to cattle, other potential hosts in the area include camels that are kept in the Bois de Mardock, a recreational center found some $15 \mathrm{~km}$ from the study site. The herd that was used for the study consisted of 42 Zebu Goudali cattle heads.

\section{Entomological prospection}

An entomological prospection was carried out for 14 days using Vavoua $(n=2)$ traps. Traps were emptied every 24 hours throughout the prospection days. Traps were placed in potential vector breeding 
environments, located in cattle pen (open grass savanna) and gallery forest.

\section{Blood collection and buffy coat preparation}

Blood was collected through the jugular veino-puncture of the 42 sampled Zebu Goudali cattle, using a vacutainer tube containing ethylenediamine tetraacetic acid (EDTA) as anticoagulant. To prepare the buffy coat, micro-capillary tubes were dipped in the whole blood and centrifuged at 12,000 revolutions per minute for 5 minutes using a micro-haematocrit centrifuge (Hawksley, UK). The capillary tubes were cut with a diamond micro-haematocrit tube cutter, few millimetres below the buffy coat. Buffy coat samples were stored at $-20{ }^{\circ} \mathrm{C}$ prior to DNA extraction.

\section{Fly preparation}

Trapped flies were individually placed in eppendorf tubes containing $1 \mathrm{ml}$ of $70 \%$ alcohol and stored at $-20^{\circ} \mathrm{C}$ prior to DNA extraction.

\section{PCR amplification and Gel electrophoresis of amplicons}

Genomic DNA from the buffy coat and flies were extracted using the Wizard Genomic DNA Purification Kit (Promega, Germany) according to the manufacturer's instructions, and then stored at $-20^{\circ} \mathrm{C}$. Generic primers were used in a nested PCR targeting kinetoplastid ITS-1 as described by Ngomtcho et al. (2017). Briefly, the first $25 \mu 1$ volume reaction contained $2 \mu \mathrm{M}$ of each outer primers (ITS1-Out Forward: CTT TGC TGC GTT CTT and ITS1-Out Reverse: TGC AAT TAT TGG TCG CGC) with product size between 180 to 640 bp, $0.2 \mathrm{mM}$ dNTP mix, 0.5 U DreamTaq DNA polymerase (Thermo Scientific, Dreieich, Germany), $1 \times$ DreamTaq buffer, and $1 \mu 1$ of extracted DNA isolates. Water and genomic DNA of $T$. grayi were added as negative and positive controls respectively.
PCR amplification was carried out as follows: initial denaturation step at $95{ }^{\circ} \mathrm{C}$ for $60 \mathrm{~s}$, followed by 30 amplification cycles with $94{ }^{\circ} \mathrm{C}$ for $60 \mathrm{~s}, 52{ }^{\circ} \mathrm{C}$ for $60 \mathrm{~s}, 72{ }^{\circ} \mathrm{C}$ for $30 \mathrm{~s}$, and final extension at $72{ }^{\circ} \mathrm{C}$ for 5 minutes. After that, the second PCR reaction was carried out with $1 \mu \mathrm{l}$ of first 1:80 diluted PCR template under the same cycling conditions as described above, except an annealing temperature of $54{ }^{\circ} \mathrm{C}$, and using the inner primer pairs (ITS1-Inner Forward: TAG AGG AAG CAA AAG, ITS1Inner Reverse: AAG CCA AGT CAT CCA TCG). $20 \mu \mathrm{l}$ of the resultant amplicons were visualized in Midori green-stained 1.5\% agarose gel.

\section{Statistical analysis}

The trap index of apparent abundance (ADT) was determined following the already published formula by Sevidzem et al., (2015) as follows:

\section{ADT \\ $=\frac{\text { Number of flies }}{\text { Number of traps } \times \text { Number of trapping days }}$}

The prevalence of trypanosomes in cattle and flies was determined as follows:

$$
\begin{aligned}
& \text { Prevalence in cattle } \\
& =\frac{\text { Number of positive cattle }}{\text { Total number of cattle screened }} \times 100 \\
& \text { Prevalence in flies } \\
& =\frac{\text { Number of positive flies }}{\text { Total number of flies screened }} \times 100
\end{aligned}
$$

The non-parametric Kruskal Wallis rank sum test of the R-statistical software 3.3.2 (R Core Team, 2016) was used to compare the ADTs of the haematophagous flies caught. The significant level of the statistical test was set at $\mathrm{p}<0.05$. 


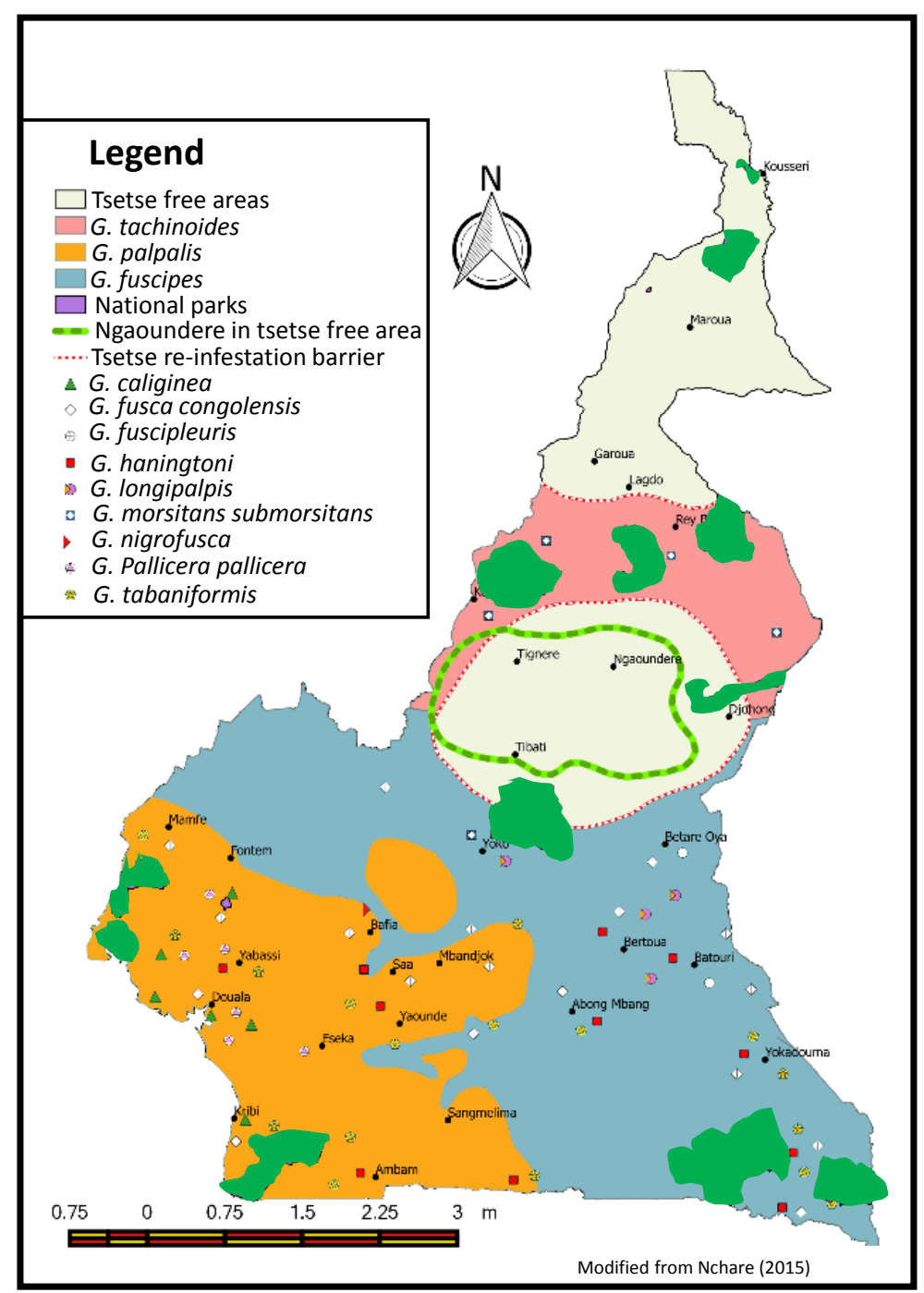

Figure 1: Tsetse fly distribution map of Cameroon with Ngaoundere as tsetse free area. Tsetse data used in this map was provided by the special mission for tsetse eradication (MSEG), Cameroon.

\section{RESULTS}

\section{Entomological findings}

Entomological prospection resulted in 127 flies grouped under two families notably Tabanidae and Stomoxyini. For Tabanidae, two genera were identified notably Chrysops (deer flies), Tabanus (horse flies) and Haematopota (clegs) with Chrysops highly represented. For the stomoxyini, only one genus was identified as Stomoxys. At the species level, the ADTs of the members of the aforementioned genera were recorded, $21 C$. longicornis (1.2 flies/trap and day), $10 \mathrm{H}$. decora (0.6 flies/trap and day), 9 T. taeniola (0.5 flies /trap and day), 6 T. gratus (0.3 flies/trap and day), $52 \mathrm{~S}$. niger niger (3.0 flies/trap and day), $14 \mathrm{~S}$. omega (0.8 flies/trap and days), $8 \mathrm{~S}$. niger bilineatus (0.4 flies per trap and day) and $7 \mathrm{~S}$. inornatus (0.2 flies per trap and day) (Table 1). There was no statistically significant difference $(\mathrm{P}>0.05)$ in the ADTs of biting flies caught. 


\section{Molecularly identified trypanosomes from cattle}

By comparing the product size from the present gel electrophoresis with the reference product sizes in literature (Ngomtcho et al., 2017), Trypanosoma theileri (4\%) and T. vivax (3\%) were detected in the cattle sample with an overall molecular prevalence of $7 \%$ (Figure 2).

\section{Molecularly identified trypanosomes from haematophagous flies}

Among the 127 haematophagous flies caught, 53 of them were screened, 10 were positive for trypanosomes, resulting in an overall fly infection rate of $18.9 \%$. There was one mix infection of $C$. longicornis with $T$. evansi and $T$. theileri. It was noticed that Haematopota decora harbored all the Trypanosoma spp. identified in the present study. C. longicornis, T. taeniola and T. gratus harbored only T. theileri (Table 1). All the Stomoxys spp screened were negative for trypanosomes.

Table 1: Flies caught/screened and the Trypanosoma spp. they harbor.

\begin{tabular}{lcccccccc}
\hline & & & & & & \multicolumn{3}{c}{ Trypanosoma spp. } \\
\cline { 6 - 8 } Species & Number & screened & ADT & nPCR & nPCR $(\%)$ & T. theileri & T. vivax & T. evansi \\
\hline C. longicornis & 21 & 21 & 1.2 & 3 & 14.3 & 2 & 1 & 1 \\
H. decora & 10 & 9 & 0.6 & 5 & 55.6 & 5 & 0 & 0 \\
T. taeniola & 9 & 7 & 0.5 & 1 & 14.3 & 1 & 0 & 0 \\
T. gratus & 6 & 4 & 0.3 & 1 & 25.0 & 1 & 0 & 0 \\
S. n. niger & 52 & 8 & 3.0 & 0 & 0.0 & 0 & 0 & 0 \\
S. omega & 14 & 2 & 0.8 & 0 & 0.0 & 0 & 0 & 0 \\
S. n. bilineatus & 8 & 1 & 0.4 & 0 & 0.0 & 0 & 0 & 0 \\
S. inornatus & 7 & 1 & 0.2 & 0 & 0.0 & 0 & 0 & 0 \\
\hline \multicolumn{1}{c}{ Total } & 127 & 53 & 7.0 & 10 & & 9 & 1 & 1 \\
\hline
\end{tabular}

nPCR: nested polymerase chain reaction, ADT: trap index of apparent abundance

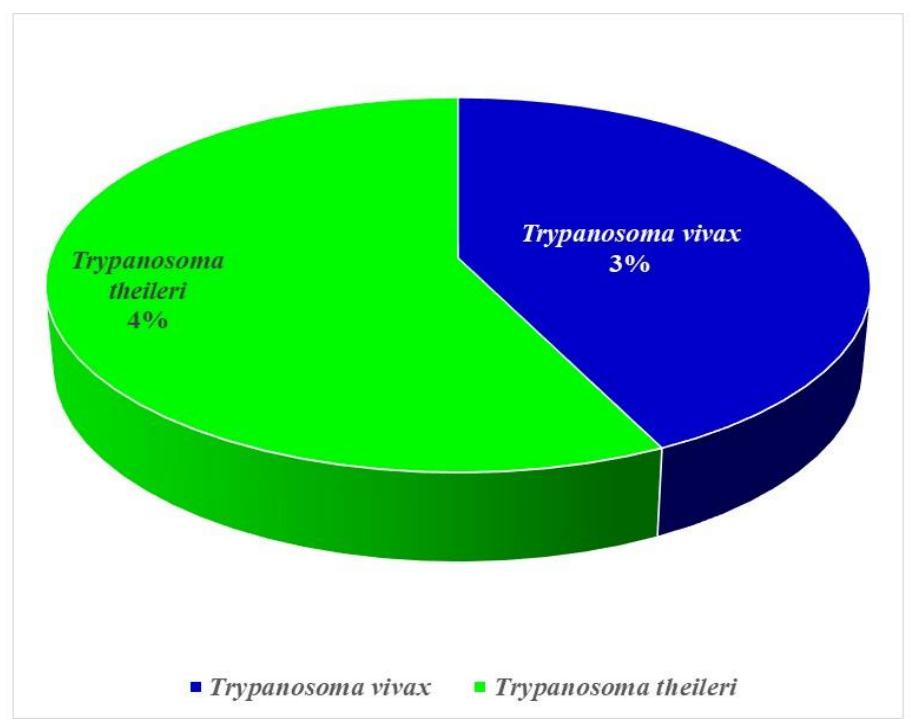

Figure 2: Trypanosoma spp. from screened cattle. 


\section{DISCUSSION}

The occurrence of tabanids and stomoxyines, mechanical vectors of bovine trypanosomiasis in the pasture area of Ngaoundere is an indication of the risk of transmission of the disease in the absence of glossines (Lendzele et al., 2019a; Sevidzem et al., 2019a; 2019b, 2019c). In the Far north region of Cameroon, there are no tsetse flies but the area is heavily infested by tabanids and stomoxyines. Suh et al. (2017) reported the occurrence of $T$. vivax in cattle from the Far North region of Cameroon, indicating the important role of mechanical vectors in transmission. The present study identified one species of the genus Chrysops (Chrysops longicornis), one species of the genus Haematopota (Haematopota decora), two species of Tabanus (Tabanus taeniola and Tabanus gratus) and four species of Stomoxys (S. n. niger, S. omega, S. n. bilineatus and S. inornatus). C. longicornis was infected with all the screened Trypanosoma spp. (T. theileri, T. vivax and T. evansi), but the positive cases of H. decora, T. taeniola and T. gratus were only from $T$. theileri. From the screening results, $H$. decora was frequently contaminated with $T$. theileri as compared to any other infected fly. These findings were not surprising as Taioe et al. (2017) and Mounioko et al. (2018) already reported that some members of the genera Tabanus, Haematopota, Philoliche, Atylotus and Ancala were positive for trypanosomes. Similarly, Boese et al. (1987) reported the cyclical transmission of $T$. theileri in Haematopota sp. The overall molecular prevalence of trypanosomes in cattle was $7 \%$ and was caused by $T$. theileri and T. vivax. These trypanosomes have been reported to be transmitted cyclically and acyclically (Boese et al., 1987; Desquesnes et al., 2003). There was no $T$. evansi detected in cattle samples of the sampled animals. This can be explained by the fact that during the sampling, wild animal host like monkeys were common in the area as well as animals from neighbouring Dawa Ranch and Centre Zootechnique that were not sampled. The absence of positive cases of trypanosomes in Stomoxys could be explained by the low number of samples screened in the present study and not their incapacity to be contaminated with trypanosomes. Stomoxys spp. have been shown to be implicated in the acyclical transmission of $T$. evansi and $T$. congolense (Sumba et al., 1997). The presence of camels in Ngaoundere might be a source of contamination of local cattle breeds and flies with $T$. evansi since camels are reservoir host of this species (Lun and Brun, 1992).

\section{Conclusion}

In a herd located in the tsetse free belt and trypanosomosis hypo-endemic rangeland of Ngaoundere, two Trypanosoma spp. ( $T$. theileri and $T$. vivax) circulates 'silently' in cattle and tabanids. Trypanosoma evansi is reported for the first time in tabanids caught from Ngaoundeere. Therefore, the role of Tabanidae and other mechanical vectors in the epizootiology of bovine trypanosomosis in tsetse free areas should not be neglected if control measures are to be taken

\section{COMPETING INTERESTS}

The authors declare that they have no competing interests.

\section{AUTHORS' CONTRIBUTIONS}

SA and SSL conceived the idea for the work and wrote the proposal; SSL, SA, AMNN, AM, AP, JFM and AZ assisted in the technical aspect of this study and in editing the manuscript. Both parties gave final approval to the manuscript.

\section{ACKNOWLEDGEMENTS}

We are grateful to the special mission for tsetse eradication for providing the traps needed for this survey. Authors thank the Baden Wurttemberg Stipendium Scholarship program (BWS-REK) for the financial support given to the second author (SSL) to conduct the molecular analysis. We thank Leif for assisting in the field survey. We equally thank Dr Renz for permitting us to work with the COBE project cattle herd.

\section{REFERENCES}

Boese R, Friedhoff KT, Olbrich S, Büscher G, Domeyer I. 1987. Transmission of 
Trypanosoma theileri to cattle by Tabanidae. Parasitol. Res., 73: 421-424.

Bosson-Vanga AH, Acapovi-Yao G, Kaba D, Dofini F, Coulibaly B, N'dri L, Kone M. 2012. Infection de Glossina palpalis palpalis par les trypanosomes le long de fleuve Comoé dans la région d'Abengourou (Cote d'Ivoire). J. Sc. Pharm. Biol., 13 (1): 31-37.

Core Team R. 2016. R: a Language and Environment for Statistical Computing. R Foundation for Statistical Computing, Vienna, Austria.

Desquesnes M, Holzmuller P, Lai DH, Dargantes A, Lun ZR, Jittaplapong S. 2013. Trypanosoma evansi and surra: A review and perspectives on origin, history, distribution, taxonomy, morphology, hosts, and pathogenic effects. Biomed. Res. Int., 194176. DOI: https://doi.org/10.1155/2013/194176

Desquesnes M, Dia ML. 2003a. Mechanical transmission of Trypanosoma congolense in cattle by the African tabanid Atylotus agrestis. Exp. Parasitol., 105: 226-231.

Desquesnes M, Dia ML. 2003b. Trypanosoma vivax: mechanical transmission in cattle by one of the most common African tabanids, Atylotus agrestis. Exp. Parasitol., 103 (1-2): 35-43.

Lendzele SS, Eisenbarth A, Zinga KRC, Mavoungou JF, Renz A. 2019. Aspects of the bionomics of hematophagous symbovine dipterans in a hyper infested rangeland of Ngaoundere (AdamawaCameroon). J. Asia-Pacific Entomol., 22: 1019-1030.

DOI: https://doi.org/10.1016/j.aspen.2019.08.0 12

Lun ZR, Brun RGW. 1992. Kinetoplast DNA and molecular karyotypes of Trypanosoma evansi and Trypanosoma equiperdum from China. Mol. Biochem. Parasitol., 50(2): 189-196.

Mamoudou A, Marceline M, Suh PF, Lendzele S, Oumarou F, Garabed R, Kingsley M, Mbunkah DA. 2016. Tabanids (Diptera: Tabanidae) fauna composition in different sites and biotopes of far-north,
Cameroon. J. Biol. Nature., 6(3): 146154.

Mbahin N, Zoli A, Mamoudou A, Tanenbe C, Abah S, Ghogum RT, Nouala SF, Njeumi F. 2006. Livestock owners perception of bovine trypanosomosis and associated treatment on the Adamaaoua plateau in Cameroon ten years after tsetse eradication. Bull. Anim. Health Prod. Africa., 54: 260-270.

Motta P, Thibaud P, Ian H, Saidou MH, Ngu NV, Tanya V, Morgan K, Rob C, Bronsvoort BMC. 2017. Implications of the cattle trade network in Cameroon for regional disease prevention and control. Sci. Rep., 7: 43932. DOI: 10.1038/srep43932 (2017).

Mounioko F, Maganga GD, Mavoungou JF, Zinga KCR, Koumba AA, Sevidzem SL, Tamesse JL, Simo G, M'batchi B. 2018. Molecular Screening of Trypanosoma spp. in Glossina, Stomoxys and Tabanids in the Moukalaba Doudou National Park (South-West, Gabon). World J. Vet. Sci., 6: 52-61.

Ngomtcho SCH, Weber J, Ngo Bum E, Terlumu GT, Kelm S, Achukwi. 2017. Molecular screening of tsetse flies and cattle reveal different Trypanosoma species including $T$. grayi and $T$. theileri in northern Cameroon. Parasit Vectors., 10: 631 .

Sevidzem SL, Tchawe R, Zinga-Koumba R, Mamoudou A, Ndjonka D, Mavoungou JF. 2019c. Insecticide coated screen models reduce insect-vector population in a pasture area in ngaoundere, Cameroon. Trends Appl. Sci. Res., 14(2): 80-89. DOI: $10.3923 /$ tasr.2019.80.89.

Sevidzem SL, Mamoudou A, Woudamyata AF, Zoli PA. 2015. Contribution to the knowledge of ecodiversity and density of tsetse (Glossinidae) and other biting flies (Tabanidae and Stomoxyinae) in the fly controlled-infested livestock/wild life interface of the Adamawa plateau Cameroon. J. Entomol. Zoo. Stud., 3: 329333.

Sevidzem SL, Zinga KCR, Acapovi-Yao GL, M'batchi B, Mavoungou JF. 2019a. 
Comparative Efficacy of Unbaited Modified Vavoua and Nzi Traps in the Capture of S. niger niger M. 1851 and $S$. calcitrans L. 1758 in NgaoundereCameroon. Arch. Vet. Sci. Med., 2: 017027. DOI: 10.26502/avsm.006.

Sevidzem SL, Mamoudou A, Dickmu S, Renz A, Acapovi-Yao GL, Mavoungou JF, Garabed R. 2019b. Risk Factors for the Contamination of Wild Stomoxys niger niger Macquart 1851 (Diptera: Muscidae) with the Foot-and-Mouth Disease Virus. Curr. Res. Agric. Sci., 6(2) : 95-108.

Sevidzem SL, Mavoungou JF, Zinga-Koumba CR, Koumba AA, Duvallet G. 2019c. Factors Influencing Seasonal and Daily Dynamics of the Genus Stomoxys Geoffroy, 1762 (Diptera: Muscidae), in the Adamawa Plateau, Cameroon. Int. J. Zoo., 2019c: 9 pages. DOI: https://doi.org/10.1155/2019/3636943.

Suh PF, Njiokou F, Mamoudou A, Ahmadou TM, Mouhaman A, Garabed R. 2017.
Bovine trypanosomiasis in tsetse-free pastoral zone of the Far-North region, Cameroon (2017). J Vector Borne Dis., 54: 263-269.

Sumba AL. 1997. Mechanical transmission of $T$. evansi and T. congolense by African Stomoxys spp. A thesis submitted in partial fulfillment for the degree of Master of Science (Medical and Veterinary Parasitology). University of Nairobi.

Taioe M, Makhosazanay MBN, Amos C. 2017. Characterisation of tabanid flies (Diptera: Tabanidae) in South Africa and Zambia and detection of protozoans parasites they are harbouring. Parasitol., 144 (9): 11621178.

Wells EA. 1972. The importance of mechanical transmission in the epidemiology of nagana: A review. Trop. Anim. Hlth. Prod., 4:74-88. 